\title{
JNK interaction with Sab mediates ER stress induced inhibition of mitochondrial respiration and cell death
}

\author{
S Win ${ }^{1,4}$, TA Than ${ }^{1,4}$, JC Fernandez-Checa ${ }^{1,2,3}$ and N Kaplowitz ${ }^{*, 1,2}$
}

Our aim was to better understand the mechanism and importance of sustained c-Jun N-terminal kinase (JNK) activation in endoplasmic reticulum (ER) stress and effects of ER stress on mitochondria by determining the role of mitochondrial JNK binding protein, Sab. Tunicamycin or brefeldin A induced a rapid and marked decline in basal mitochondrial respiration and reserve-capacity followed by delayed mitochondrial-mediated apoptosis. Knockdown of mitochondrial Sab prevented ER stressinduced sustained JNK activation, impaired respiration, and apoptosis, but did not alter the magnitude or time course of activation of ER stress pathways. P-JNK plus adenosine $5^{\prime}$-triphosphate (ATP) added to isolated liver mitochondria promoted superoxide production, which was amplified by addition of calcium and inhibited by a blocking peptide corresponding to the JNK binding site on Sab (KIM1). This peptide also blocked tunicamycin-induced inhibition of cellular respiration. In conclusion, ER stress triggers an interaction of JNK with mitochondrial Sab, which leads to impaired respiration and increased mitochondrial reactive oxygen species, sustaining JNK activation culminating in apoptosis.

Cell Death and Disease (2014) 5, e989; doi:10.1038/cddis.2013.522; published online 9 January 2014

Subject Category: Experimental Medicine

Mitochondria are important target organelles in cell death signaling pathways in different experimental and disease models including endoplasmic reticulum (ER) stress or metabolic stress induced cell death. ${ }^{1,2}$ In in-vivo or in-vitro models, sustained activation of c-Jun N-terminal kinase (JNK) is an effector signaling molecule strongly associated with cell death. ${ }^{3}$ The mechanism of sustained JNK activation by different pathways depends on the context of the experimental model used and activation of signaling molecules including source of reactive oxygen species (ROS). In acetaminophen (APAP)-induced hepatocyte death or acute liver failure where mitochondria are the primary targeted organelles, we found massive activation of JNK within a short period, and sustained JNK activation accompanied the release of ROS from mitochondria leading to upstream activation of the mitogen-activated protein (MAP) kinase cascade. ${ }^{4}$ The activation loop was initiated and amplified by binding of activated JNK (P-JNK) to the outer mitochondrial membrane protein Sab (SH3 homology associated BTK binding protein) and subsequent inhibition of mitochondrial respiration. ${ }^{5}$ Silencing of Sab inhibited translocation of P-JNK to mitochondria and sustained activation of JNK, and prevented APAP or galactosamine/tumor necrosis factor (TNF)- $\alpha$ induced mouse liver injury and hepatocyte death. ${ }^{5}$ Furthermore, others have shown that inhibition of P-JNK binding to Sab using a Sab ${ }_{\text {Kim } 1}$ peptide corresponding to the P-JNK binding site of Sab prevented ischemic necrosis in heart ${ }^{6}$ and brain. ${ }^{7}$

In severe ER stress induced by tunicamycin or brefeldin A (BFA), apoptotic cell death is preceded by mitochondrial cytochrome $c$ release and caspase activation. In different ER stress studies, several signaling mechanisms linking ER stress and mitochondrial cell death pathway have been proposed. ${ }^{8-10}$ These include IRE1 $\alpha \rightarrow$ TRAF2 $\rightarrow$ ASK1 $\rightarrow$ JNK,

${ }^{1}$ Division of Gastrointestinal and Liver Diseases, Keck School of Medicine, University of Southern California Research Center for Liver Diseases, University of Southern California, Los Angeles, CA 90089-9121, USA; ${ }^{2}$ Southern California Research Center for ALPD and Cirrhosis, Keck School of Medicine of the University of Southern California, Los Angeles, CA, USA and ${ }^{3}$ Department of Cell Death and Proliferation, Institute of Biomedical Research of Barcelona (IIBB), Consejo Superior Investigaciones Cientificas (CSIC) and Liver Unit-Hospital Clinic and CIBEREHD, Barcelona, Spain

*Corresponding author: N Kaplowitz, Division of Gastrointestinal and Liver Diseases, Keck School of Medicine, University of Southern California Research Center for Liver Diseases, University of Southern California, 2011 Zonal Ave., HMR 101, Los Angeles, CA 90089-9121, USA. Tel: +323442 5576; Fax: +3234423243; E-mail: kaplowit@usc.edu

${ }^{4}$ These authors contributed equally to this work.

Keywords: apoptosis; oxidative stress; reactive oxygen species; signal transduction; hepatocytes; HeLa cells

Abbreviations: APAP, acetaminophen; ASK1, mitogen-activated protein kinase kinase kinase 5; ATF-6, Activating transcription factor 6; ATP, Adenosine $5^{\prime}$-triphosphate; Bcl2, B-cell lymphoma 2; Bcl-X $\mathrm{L}$, B-cell lymphoma-extra-large; BFA, brefeldin A; BHA, butylated hydroxyanisole; $\mathrm{Ca}^{2+}$, calcium; CaMKII- $\gamma$, calcium/ calmodulin-dependent protein kinase II gamma; CCCP, Carbonyl cyanide 3-chlorophenylhydrazone; CHOP, DNA-damage-inducible transcript 3; EACR, extracellular acidification rate; ER, endoplasmic reticulum; ERO1 $\alpha$, endoplasmic reticulum oxidoreductin- $1 \alpha$; Fas, TNF receptor superfamily member; GRP78, glucose-regulated protein $78 \mathrm{kDa}$; IP3, inositol 1,4,5-trisphosphate; IP3R, inositol 1,4,5-trisphosphate receptor; IRE1 $\alpha$, Inositol-requiring enzyme-1 $\alpha$; JNK $(\mathrm{a})$, active JNK; JNK (m), inactive JNK; JNK, c-Jun N-terminal kinase; JNKi, JNK inhibitor SP600125; MAP kinase, mitogen-activated protein kinase; Mcl-1, myeloid cell leukemia sequence 1; MOMP, Mitochondrial outer membrane permeabilization; MPT, mitochondrial permeability transition; $\mathrm{O}_{2}$, superoxide; OCR, oxygen consumption rate; Ox-Phos, oxidative phosphorylation; PERK, eukaryotic translation initiation factor 2-alpha kinase; PMH, primary mouse hepatocyte; RCR, respiratory-control-ratio; Reserve-capacity, reserve oxidative capacity; RIP1, receptor-interacting serine-threonine kinase1; ROS, reactive oxygen species; Sab, SH3 homology associated BTK binding protein; sXBP1, spliced X-box binding protein 1; Tm, tunicamycin; TNF, tumor necrosis factor; TRAF2, TNF receptor-associated factor 2; UPR, unfolded protein response; XBP1, $X$-box binding protein 1

Received 06.9.13; revised 23.11.13; accepted 25.11.13; Edited by H-U Simon 
and $\mathrm{PERK} \rightarrow \mathrm{CHOP} \rightarrow \mathrm{ERO} 1 \alpha \rightarrow \mathrm{IP} 3 \mathrm{R} \rightarrow \mathrm{CaMKII}-\gamma$ with both pathways resulting in activation of $\mathrm{BH} 3$ only domain proteins, generation of mitochondrial derived ROS, impaired insulin receptor signaling and induction of Fas expression. ${ }^{11-15}$ Malfolded protein initiates ER stress and unfolded protein response (UPR) is activated through IRE $1 \alpha$, PERK, and activating transcription factor 6 (ATF-6) signaling pathways. Malfolded protein induces dimerization of IRE $1 \alpha$, which activates the kinase domain, initiating the MAP kinase pathway via recruitment of TRAF2, RIP1, and ASK1, and also activates the endonuclease domain, which splices $X$-box binding protein 1 (XBP1) mRNA to spliced (s) XBP1 for UPR gene expression. ${ }^{16}$ Activation of MAP kinase, downstream of IRE $1 \alpha$ dimerization, is an early event occurring before changes of global gene expression mediated by SXBP1 or the ER generation of ROS by the P-PERK $\rightarrow \mathrm{CHOP} \rightarrow$ ERO1 $\alpha .{ }^{17,18}$ JNK activation is sustained in severe ER stress-induced cell death, though the mechanism of how JNK activation is sustained has yet to be defined. Furthermore, the contribution of ROS and its source (mitochondrial or ER) to sustained JNK activation and the contribution of P-JNK interaction with mitochondria to ER stress-induced cell death has not been defined. In primary mouse hepatocytes (PMHs), tunicamycin $(5 \mu \mathrm{g} / \mathrm{ml})$ inhibition of protein glycosylation leads to accumulation of malfolded protein followed by $\mathrm{Ca}^{2+}$ release into cytosol in the early phase of ER stress. ${ }^{19-21}$ As cell death is delayed, the role of early calcium release on mitochondria and cell death are not well understood. However, prolonged severe ER stress depletes ER calcium stores, further impairing protein folding in the ER. BFA primarily impedes protein transport from the endoplasmic reticulum to the Golgi complex resulting in markedly dilated endoplasmic reticulum. $^{22}$

In this paper, we have identified that P-JNK interaction with $\mathrm{Sab}$ is a key event in the perturbation of mitochondrial ATP producing respiration in tunicamycin or BFA-induced ER stress and has a major role in cell death induced by ER stress in hepatocytes and HeLa cells.

\section{Results}

ER stress inhibits mitochondrial respiration. Tunicamycin and BFA are widely used ER stress inducers. Tunicamycin inhibits protein glycosylation in the ER leading to ER stress due to protein malfolding. BFA causes a rapid accumulation of proteins within the ER and collapse of the Golgi stacks. We examined the effect of a range of tunicamycin concentrations on hepatocyte viability and found dose related toxicity with minimal effect at $10 \mu \mathrm{g} / \mathrm{ml}$ and marked effect at $20 \mu \mathrm{g} / \mathrm{ml}$ (65\% cell death at $24 \mathrm{~h}$, Figure 1a), which was preceded by caspase 3 activation and cytochrome $c$ release at $4 \mathrm{~h}$ (Figures $1 \mathrm{~b}$ and $\mathrm{c}$ ). Tunicamycin-induced cell death by SYTOX-green nuclear staining did not appear until after $8 \mathrm{~h}$. To investigate the involvement of mitochondria in ER stress induced $\mathrm{PMH}$ apoptosis, we examined the real-time changes of cellular and mitochondrial oxygen consumption rate (OCR). Cellular OCR declined gradually over $2 \mathrm{~h}$ in tunicamycin $(20 \mu \mathrm{g} / \mathrm{ml})$ treated PMH (Figure 1d). Tunicamycin $20 \mu \mathrm{g} / \mathrm{ml}$ significantly decreased mitochondrial oxidativephosphorylation (Ox-Phos) and reserve oxidative capacity (reserve-capacity) after $1 \mathrm{~h}$ and $2 \mathrm{~h}$ of treatment, whereas proton leak, which functions to dampen ROS generation, ${ }^{23}$ was increased at $1 \mathrm{~h}$ but decreased significantly at $2 \mathrm{~h}$ of treatment (Figure 1e). Non-mitochondrial OCR was not changed significantly (not shown). Consistent with tunicamycin-induced ER stress, BFA (10-20 $\mu \mathrm{g} / \mathrm{ml})-$ induced ER stress also increased cell death (Supplementary Figure S1A), and inhibited mitochondrial OCR of $\mathrm{PMH}$ (Supplementary Figure S1B). In addition, ER stress induced by tunicamycin or BFA increased HeLa cell death (Supplementary Figures S2A and S3A) and inhibited mitochondrial OCR (Supplementary Figure S4).

Involvement of JNK in ER stress induced inhibition of mitochondrial respiration and cell death. Next, we looked at the time course of activation of ER stress transducers. As expected, the ER resident stress sensors PERK (P-PERK) (Figure 2b) and ER stress response protein expression (CHOP) (Figure 2b) increased after 4-8 h, whereas JNK was activated earlier and was sustained (Figure 2a). Activation of JNK $(P-J N K)$ as a downstream target of IRE1 $\alpha$ kinase domain activation (Figure 2a), and spliced XBP1 mRNA (Figure $3 c$ ) as a response to activation of endonuclease domain of IRE $1 \alpha$ increased after $1-8 \mathrm{~h}$. Inhibition of JNK activation by SP600125 (JNKi) selectively and significantly blocked sustained P-JNK activation, whereas SP600125 did not prevent P-PERK activation and CHOP expression (Figure $2 b$ ). To investigate the link between tunicamycininduced P-JNK activation and involvement of mitochondria in ER stress, we examined the changes of cellular and mitochondrial OCR induced by tunicamycin with or without JNKi. Tunicamycin inhibition of cellular and mitochondrial Ox-Phos OCR was significantly prevented by SP600125 (JNKi) co-treatment (Figure 2c), but ER stress induced inhibition of anaerobic glycolysis (extracellular acidification rate (EACR)) after carbonyl cyanide 3-chlorophenylhydrazone (CCCP) injection was not affected (Supplementary Figure S5). Moreover, JNKi inhibited caspase 3 cleavage (not shown) and significantly prevented cell death (Figure 2d). JNK activation by BFA-induced ER stress in $\mathrm{PMH}$ was inhibited by JNKi (Supplementary Figure S1C). JNKi also prevented tunicamycin or BFA induced ER stressmediated HeLa cells death (Supplementary Figures S2B and S3B) by inhibiting ER stress-mediated JNK activation (Supplementary Figures S2C and S3C). Therefore, JNK is a key mediator of tunicamycin or BFA-induced impairment of mitochondrial respiration and apoptosis.

Involvement of mitochondrial Sab in ER stress inhibition of mitochondrial respiration and induction of cell death. P-JNK activation and translocation to mitochondrial Sab have a key role in APAP and TNF/galactosamine induced hepatotoxicity and in ischemia-reperfusion injury of brain and heart. Activation and translocation of JNK to mitochondria have been shown to inhibit mitochondrial state 3 respiration and respiratory-control-ratio (RCR) in the APAP induced hepatocyte injury model ${ }^{4}$ and in HeLa cells. ${ }^{24}$ Knockdown of Sab by shRNA prevents the hepatic necrosis and $\mathrm{PMH}$ death, and blocking of Sab-P-JNK binding by Sab ${ }_{\mathrm{KIM} 1}$ peptide prevents brain and cardiac ischemic necrosis. ${ }^{5-7}$ 
a
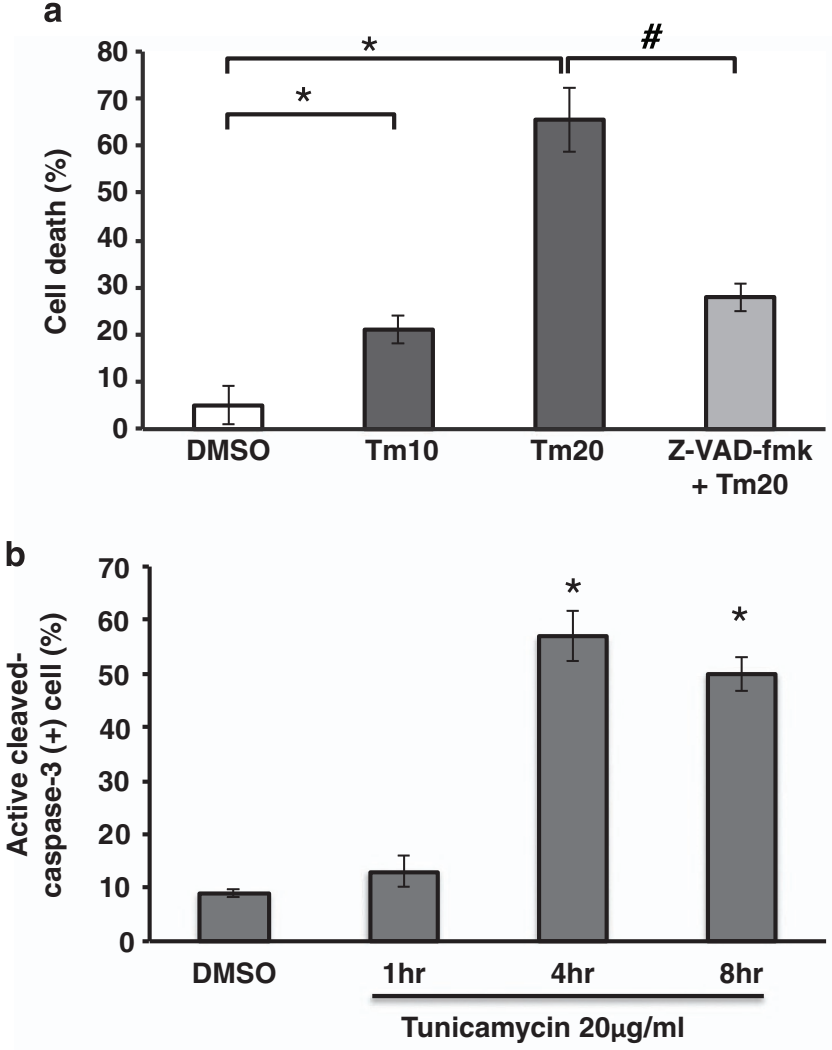

C

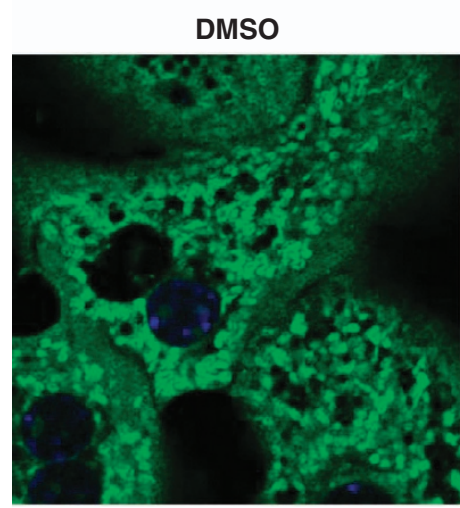

Anti-Cyt C

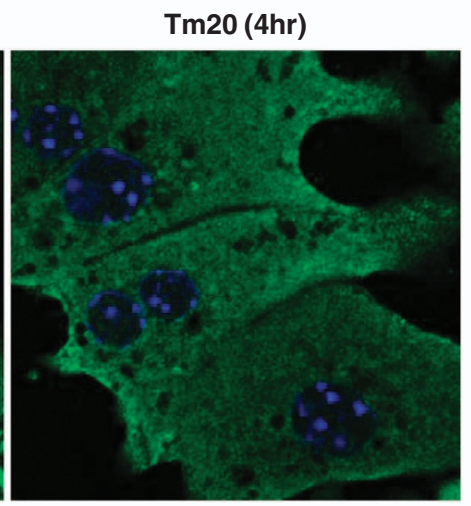

d

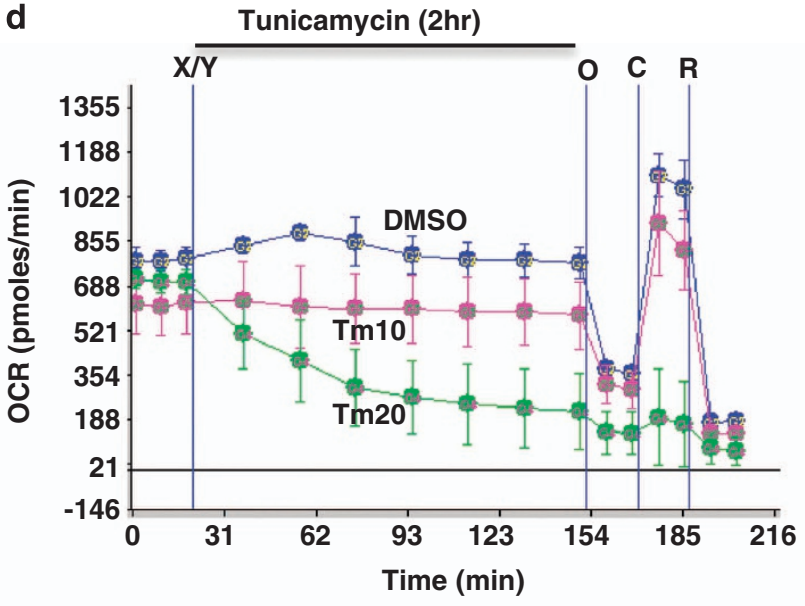

e Mitochondrial Ox-Phos

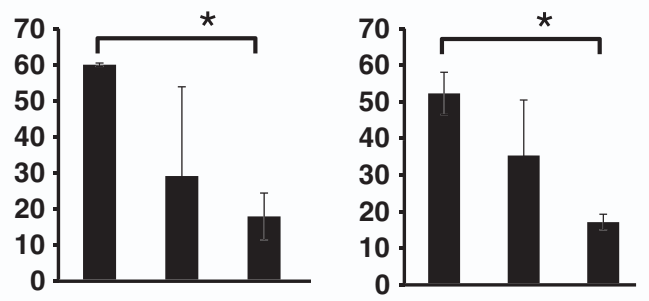

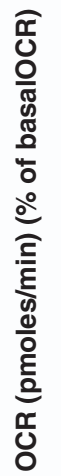

Mitochondrial Reserve-capacity

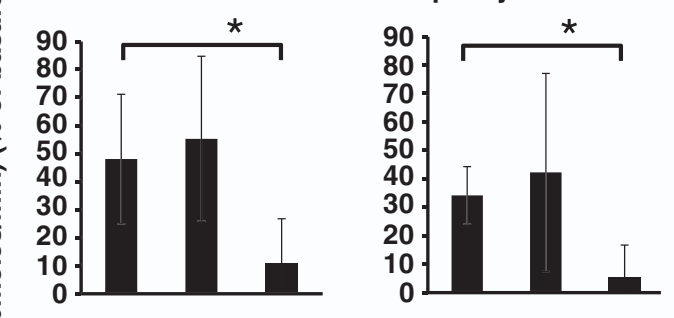

Mitochondrial Proton leak

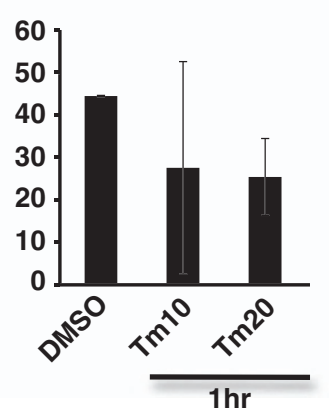

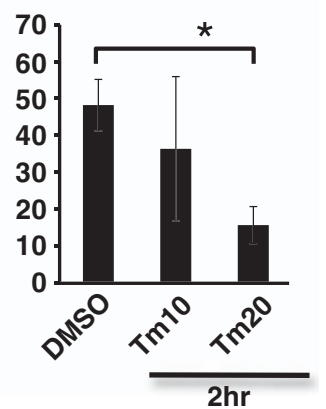

Figure 1 Tunicamycin induced cell death and inhibition of mitochondrial respiration. (a) Cell death (Sytox-green staining) at $24 \mathrm{~h}$ after tunicamycin (Tm) $10 \mathrm{and} 20 \mu \mathrm{g} / \mathrm{ml}$ treatment (Tm10 and Tm20); ${ }^{*} P<0.01$ versus DMSO. Z-VAD-fmk $(10 \mu \mathrm{M})$ prevented tunicamycin-induced cell death; \#P<0.01 versus Tm20. $N=6$ experiments. (b) Quantitation of immunostained active cleaved-caspase-3 positive cells after tunicamycin treatment; ${ }^{*} P<0.01$ versus DMSO. $N=3$ experiments. (c) Cytochrome $C$ released after tunicamycin treatment (confocal image; $63 \mathrm{X}$ magnification). (d) Real-time continuous measurement of cellular and mitochondrial respiration (OCR) using in Seahorse XF24 analyzer. After acquisition of basal (starting) OCR, DMSO or tunicamycin 10-20 $\mu \mathrm{g} / \mathrm{ml}$ was injected (marked as X/Y). Mitochondrial OCR after injection oligomycin (O), CCCP (C) or rotenone (R) was acquired at the end of cellular OCR measurement. No loss of viability was observed during these incubations (not shown). (e) Mitochondrial Ox-Phos OCR (OCR at 1 or $2 \mathrm{~h}-\mathrm{OCR}$ after oligomycin) reflecting mitochondrial ATP generation, mitochondrial reserve-capacity (OCR after 1 or $2 \mathrm{~h}-\mathrm{OCR}$ after CCCP), and proton leak (OCR after oligomycin-OCR after rotenone injection) were calculated from acquired mitochondrial OCR. The data are presented as mean \pm S.D. Mean of five wells for each experiment; ${ }^{*} P<0.05$ versus DMSO, $N=5$ experiments 
a
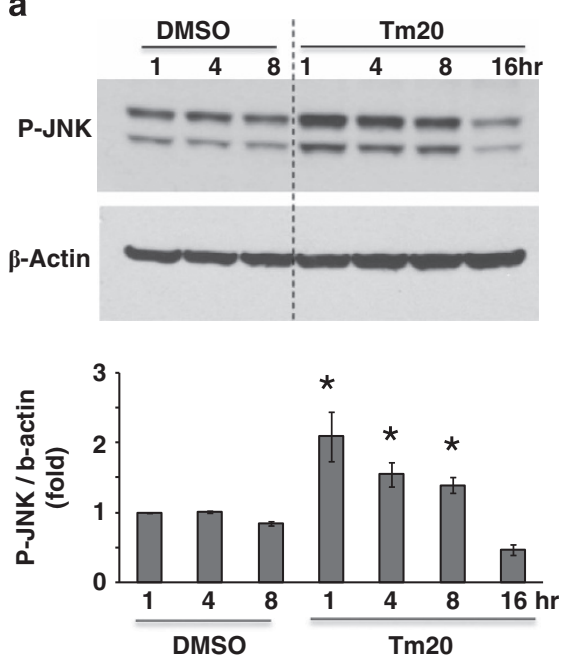

b
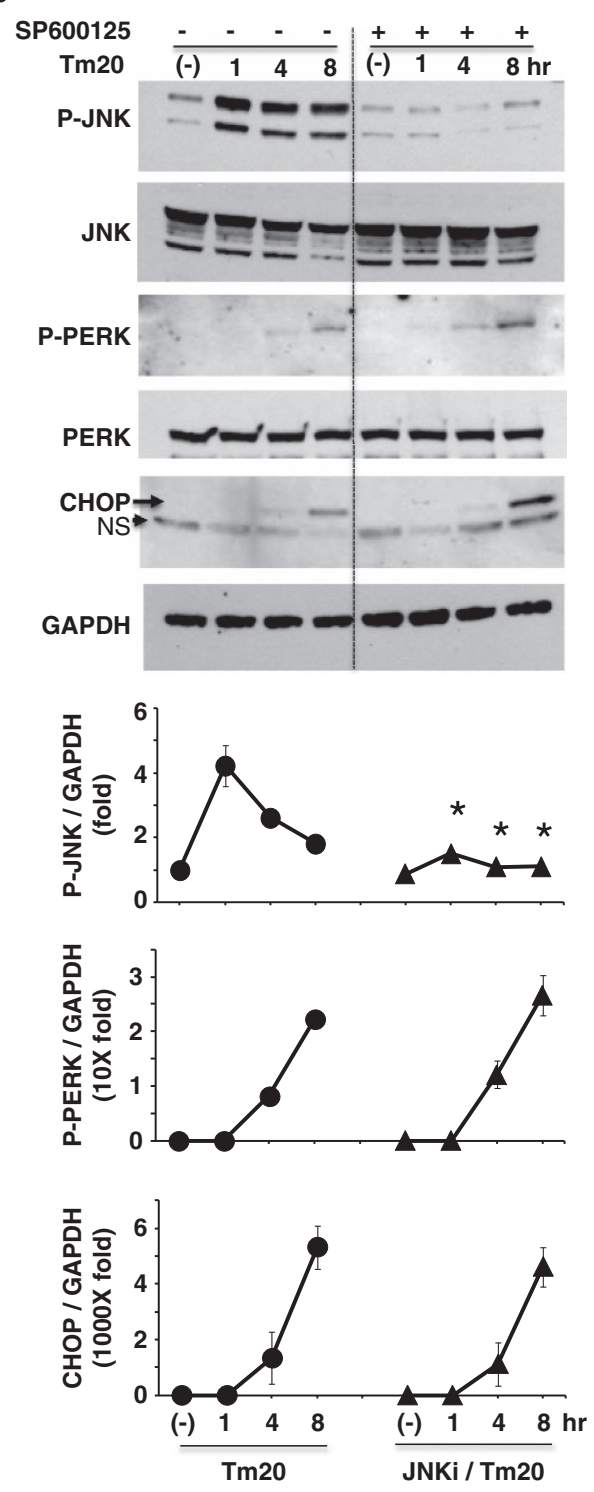

C
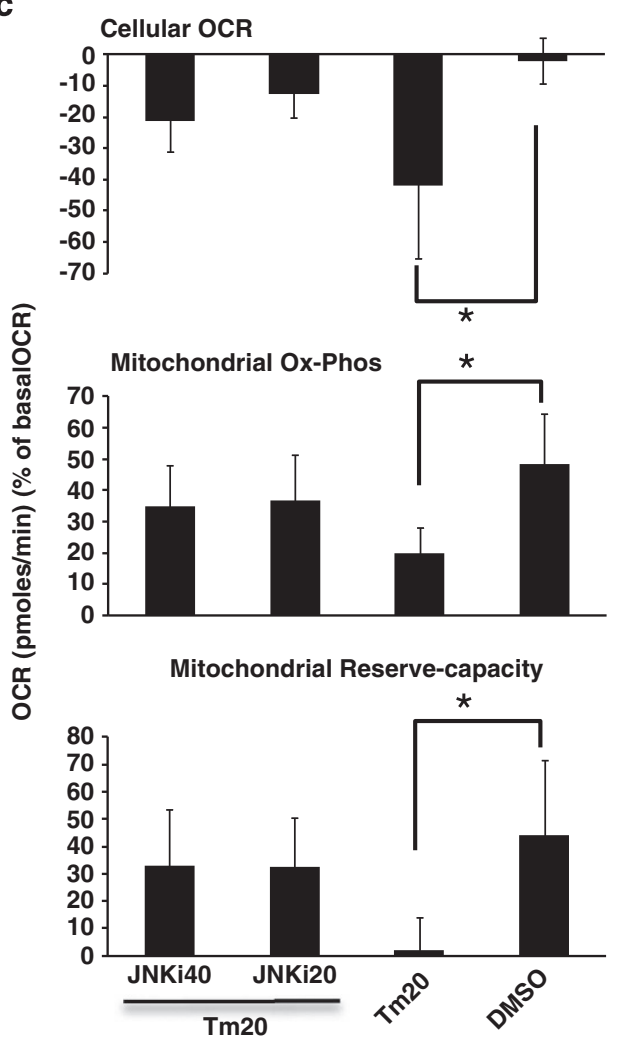

d

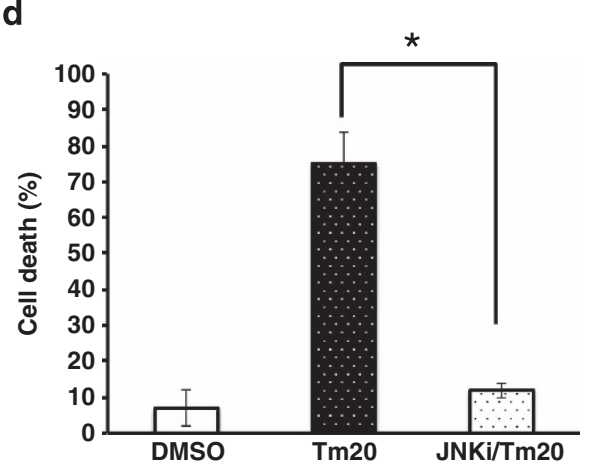


Thus, to further define the role of JNK in inhibition of mitochondrial Ox-Phos by ER stress in $\mathrm{PMH}$, we examined the effect of silencing of Sab expression on tunicamycin $(20 \mu \mathrm{g} / \mathrm{ml})$ induced ER stress response, cellular and mitochondrial respiration, and cell death. Knockdown of Sab did not significantly change the tunicamycin-induced intensity and chronology of P-PERK activation, CHOP, sXBP1 mRNA, (and glucose-regulated protein $78 \mathrm{kDa}$ (GRP78), not shown) expression (Figures $3 a$ and $\mathrm{c}$ ). Basal level of ER stress sensors IRE1 $\alpha$ (not shown), PERK protein levels were not changed by silencing of Sab (Figure 3a). Thus, the ER stress response was not perturbed by silencing of Sab. In shlacZ control $\mathrm{PMH}$, JNK activation was rapidly and significantly enhanced above basal level at $15 \mathrm{~min}$ (initial activation) after tunicamycin treatment, further increasing from 30 to $60 \mathrm{~min}$ followed by a gradual decline to $8 \mathrm{~h}$. In Sab-silenced $\mathrm{PMH}$ and HeLa cells, initial JNK activation (15 min) was similar to the intensity in tunicamycin-treated shlacZ control PMH, but thereafter P-JNK activation was significantly inhibited (Figures $3 a$ and b and Supplementary Figure S2D). Silencing Sab expression protected against tunicamycin-induced cytochrome $c$ release (Supplementary Figure S6) and $\mathrm{PMH}$ death (Figure $3 d$ ) and HeLa cell death (Supplementary Figure S2E), and significantly prevented tunicamycininduced inhibition of cellular and mitochondrial OCR (Figure 3e, Supplementary Figure S4). This suggested that ER stress targets and inhibits mitochondrial respiration through initial P-JNK activation from ER, which is then sustained by the interaction of P-JNK with mitochondrial Sab. Silencing of Sab in PMH and HeLa cells also prevented BFA-induced ER stress-mediated sustained JNK action (Supplementary Figures S1D and S3D) and cell death (Supplementary Figures S1E and S3E) but not by eliminating ER stress (Supplementary Figures S1F and S3F). Decreased mitochondrial OCR by BFA-induced ER stress was also prevented in Sab-silenced $\mathrm{PMH}$ and HeLa cells (Supplementary Figures S1G and S4).

To further investigate whether tunicamycin induced P-JNK activation and inhibition of mitochondrial respiration was dependent on mitochondrial protein Sab, we measured the cellular and mitochondrial OCR of $\mathrm{PMH}$ incubated with tunicamycin with either membrane permeant scrambled peptide or $\mathrm{Sab}_{\mathrm{Kim} 1}$ peptide. $^{25} \mathrm{Sab}_{\mathrm{Kim} 1}$ peptide prevented tunicamycin-induced inhibition of cellular OCR and mitochondrial Ox-Phos and prevented the decrease of mitochondrial reserve-capacity (Figure $3 \mathrm{f}$ ). To rule out a direct effect of tunicamycin on mitochondria, we measured OCR in isolated mouse liver mitochondria and observed no inhibition (Supplementary Figure S7).

As JNK can be activated by ROS and because mitochondrial dysfunction can result in ROS production, we next examined the effect of antioxidant treatment in the link between ER stress and mitochondrial perturbation and cell death. Antioxidant butylated hydroxyanisole (BHA) significantly inhibited sustained JNK activation from 30 min to $8 \mathrm{~h}$ but did not inhibit the initial (15 min) activation (Figure 4b), which is likely derived directly from the ER. P-PERK activation, CHOP and GRP78 expression were not significantly changed by $\mathrm{BHA}$ pretreatment (Figure 4a). BHA also inhibited cell death (Figure 4c). This suggested that mitochondrial oxidants (ROS) contribute to P-JNK activation after the initial ER stress activation. In tunicamycin-induced ER stress models, the source of ROS can be contributed to by ERO1 $\alpha$ in ER or by inhibition of mitochondrial electron transport. The lack of inhibition of initial JNK activation by $\mathrm{BHA}$ favors the latter. Therefore, we examined the generation of ROS from isolated mitochondria exposed to recombinant active $\mathrm{P}-\mathrm{JNK}$ by measuring superoxide $\left(\mathrm{O}_{2}^{\bullet-}\right)$ production. ROS was increased after exposure to P-JNK plus ATP (but not by either one alone). The requirement for ATP supports earlier work showing that P-JNK phosphorylates Sab. ${ }^{26}$ ROS was significantly blocked by $\mathrm{Sab}_{\mathrm{Kim} 1}$ peptide but not by scrambled peptide (Figure 4d). Prevention of sustained $\mathrm{P}$-JNK activation by silencing of Sab or by BHA suggests that mitochondria are the major source of ROS and that ROS promote the sustained JNK activation through a self-amplifying mechanism that leads ultimately to cell death (Figure 4f).

As $\mathrm{ER} \mathrm{Ca}^{2+}$ release in response to tunicamycin could affect mitochondrial respiration, we assessed the role of $\mathrm{Ca}^{2+}$. The inhibition of $\mathrm{PMH}$ mitochondrial respiration by tunicamycin and sustained JNK activation was not affected by CaMKII inhibitor, calcium uniporter inhibitor or chelation of calcium (Supplementary Figure S8), indicating that the early inhibitory effects of tunicamycin on mitochondrial respiration are dependent on the JNK-Sab interaction but independent of calcium. Of note inositol 1,4,5-trisphosphate (IP3) induced ER calcium release increased OCR (Supplementary Figure S8). As $\mathrm{Ca}^{2+}$ enhanced mitochondrial respiration, we determined the effect of $\mathrm{Ca}^{2+}$ on the time course and extent of superoxide production by isolated mitochondria exposed to active JNK $\left(\mathrm{JNK}_{(\mathrm{a})}\right)$ or inactive $\left.\mathrm{JNK}_{(\mathrm{JNK}}(\mathrm{m})\right) \cdot \mathrm{Ca}^{2+}(50 \mathrm{nM})$ increased the level and duration of MitoSOX fluorescence in the presence of active but not with inactive JNK (Figure 4e). $\mathrm{Ca}^{2+}$ also increased ROS generation in antimycin A-treated mitochondria (not shown).

\section{Discussion}

The goal of the present study was to elucidate the role of the $\mathrm{P}$-JNK $\rightarrow$ mitochondrial Sab $\rightarrow$ ROS self-amplification loop in ER stress induced mitochondrial dysfunction and cell death. In many cellular contexts it has been recognized that ER and mitochondrial stress and dysfunction accompany each other, but the mechanism for the interplay of these two closely associated organelles in the cell death response to ER stress is poorly understood. ${ }^{27,28}$ We and others have described an

Figure 2 Effect of ER stress induced P-JNK activation on mitochondrial respiration and PMH death. (a) $20 \mu \mathrm{g} / \mathrm{ml}$ tunicamycin treatment increased P-JNK above basal for $8 \mathrm{~h} ;{ }^{*} P<0.05$ versus DMSO. (b) JNKi blocked basal and tunicamycin $20 \mu \mathrm{g} / \mathrm{ml}$ induced JNK activation, but P-PERK activation and CHOP expression were not affected; ${ }^{*} P<0.05$ versus no JNKi at each time by densitometry, $N=5$ experiments. (c) JNKi prevented tunicamycin $20 \mu \mathrm{g} / \mathrm{ml}$ inhibition of mitochondrial Ox-Phos and reservecapacity. The data are presented as means \pm S.D of five wells of each sample for each experiment, ${ }^{\star} P<0.05, N=5$ experiments. (d) SP600125 (JNKi) $20 \mu \mathrm{M}$ prevented tunicamycin $20 \mu \mathrm{g} / \mathrm{ml}$ induced PMH death, ${ }^{*} P<0.01, N=5$ experiments. (See also Supplementary Figure S1) 
a
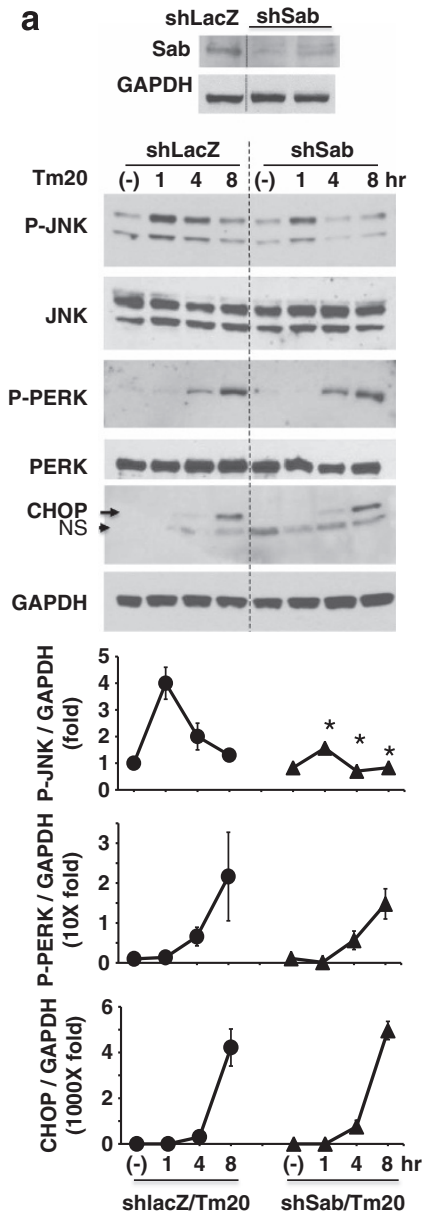

b
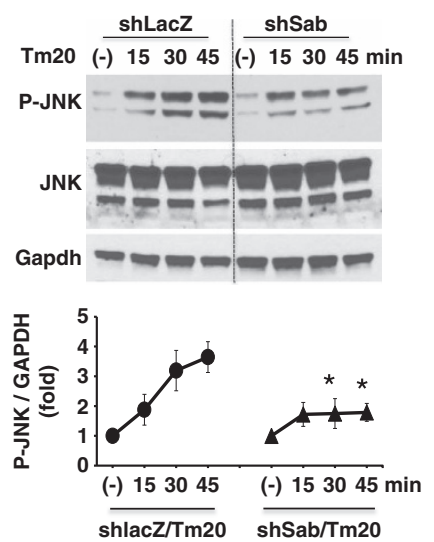

C
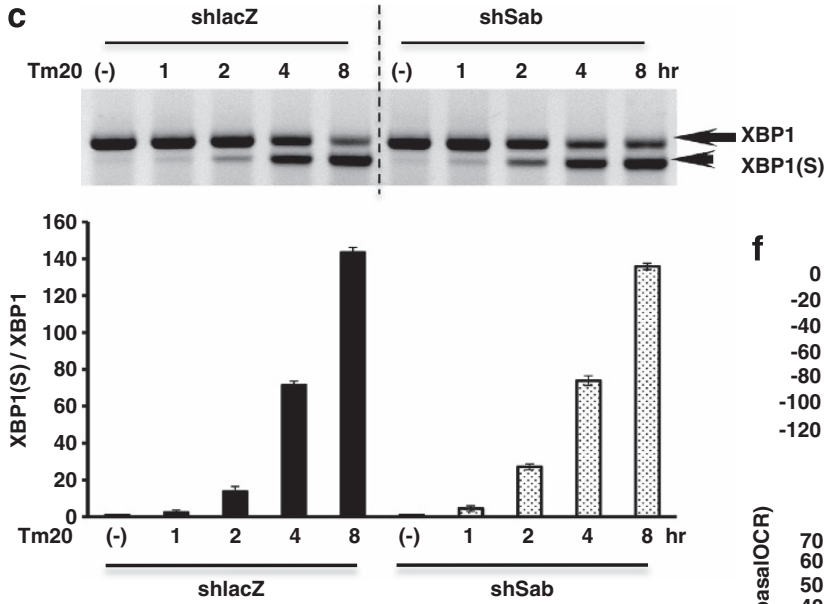

f

f Cellular OCR
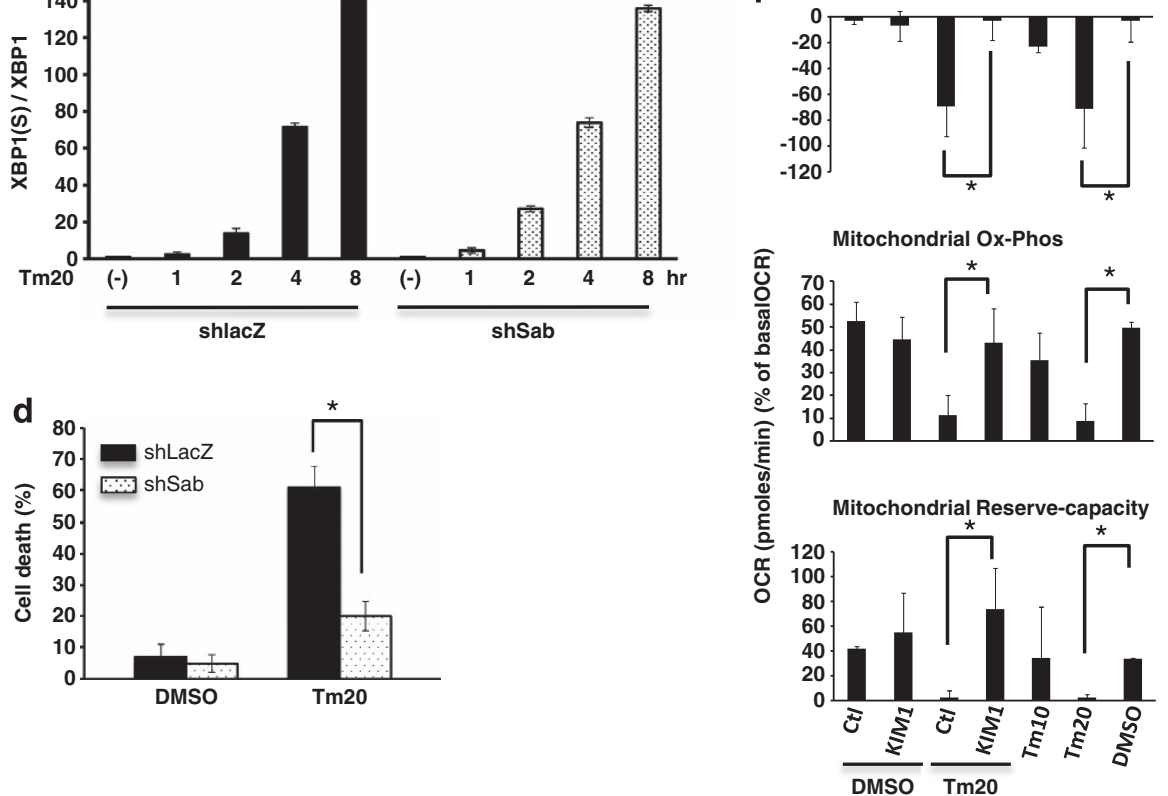
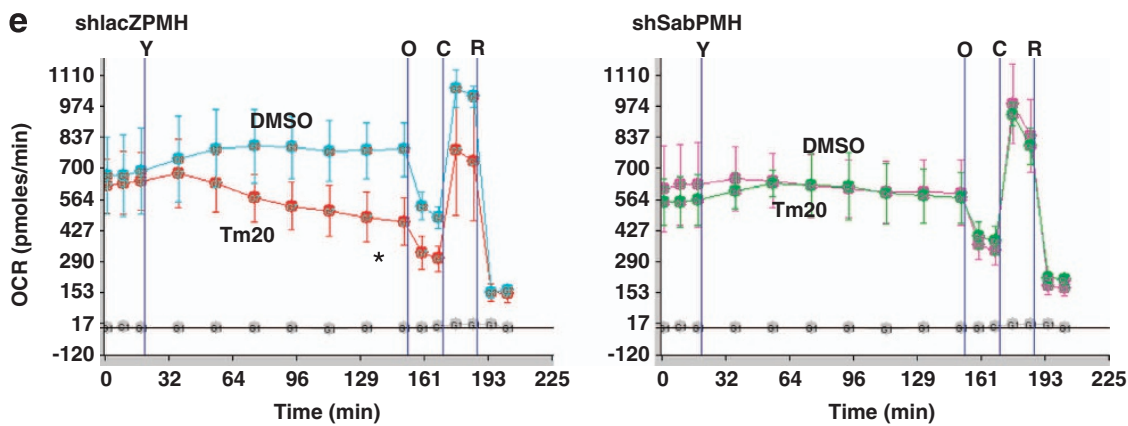

Figure 3 Effect of knockdown of Sab or Sab KIM1 $_{1}$ peptide on ER stress induced sustained P-JNK activation, PMH death and cellular and mitochondrial respiration. (a) PMH were isolated 10 days after tail-vein injection with adenoviral shlacZ or shSab. shSab efficiently depleted Sab protein. Knockdown of Sab suppressed sustained JNK activation (1-8 h); ${ }^{*} P<0.05$ versus shlacZ, $N=5$ experiments. The increase of P-PERK activation and CHOP expression were not changed by knockdown of Sab. (b) Knockdown of Sab blunted JNK activation at 30 and 45 min after tunicamycin treatment but not initial activation at $15 \mathrm{~min}$. (c) XBP1(S) (spliced form) was observed at same time after tunicamycin treatment of PMH without or with Sab knockdown. (d) Knockdown of Sab inhibited tunicamycin-induced cell death by SYTOX-green assay; ${ }^{*} P<0.01$ versus shlacZ, $N=5$ experiments. (e) Tunicamycin inhibition of OCR was prevented by knockdown of Sab during $2 \mathrm{~h}$ continuous tracing after tunicamycin injection; ${ }^{*} P<0.05, N=5$ experiments. Tunicamycin $20 \mu \mathrm{g} / \mathrm{ml}$ injection was marked as ' $\mathrm{Y}$ '. Oligomycin (O), CCCP (C), Rotenone (R). (f) Wild type PMH cellular OCR, mitochondrial oxidativephosphorylation, and mitochondrial reserve oxidative capacity were measured for $2 \mathrm{~h}$ after injection of DMSO or tunicamycin with control scrambled peptide (Ctl) or Sab $\mathrm{KIM}_{1}$ peptide (KIM1) $10 \mu \mathrm{M}$; ${ }^{*} P<0.05$ Ctl peptide versus KIM1 peptide or Tm20 versus DMSO, $N=5$ experiments. The data are presented as mean \pm S.D. Mean of five wells of each experiment. (See also Supplementary Figure S2) 
important self-amplification loop involving JNK activation by toxins, TNF, and ischemia-reperfusion leading to binding of P-JNK to Sab on the outer mitochondrial membrane, which then promotes mitochondrial ROS production by a mechanism not yet fully understood. ${ }^{4,5}$ ROS release then further activates MAPK cascade, and the self-amplification results in sustained JNK activation leading either to ROS mediated mitochondrial permeability transition (MPT)-induced necrosis (as seen in APAP toxicity) or B-cell lymphoma 2 (Bcl2) family mediated mitochondrial outer membrane permeabilization (MOMP)induced apoptosis (as seen in the TNF/galactosamine model of liver injury).

JNK is known to be activated by ER stress through the IRE1 $\alpha$ pathway, ${ }^{11}$ but the interplay with mitochondria and the mechanism for sustained JNK activation in ER stress is not known. Therefore, we hypothesized that the initial JNK activation in the ER is followed by its interplay with mitochondrial Sab, leading to impaired mitochondrial function and amplification of mitochondrial ROS release and that this self-amplification loop has a key role in ER stress-induced cell death. To test this hypothesis, we induced ER stress in $\mathrm{PMH}$ and HeLa cells using tunicamycin, a widely used specific inducer of ER stress through inhibition of protein glycosylation and unfolded protein accumulation or BFA, an inhibitor of protein transport from the endoplasmic reticulum to the Golgi. Immediate JNK activation as fast as 15 min after tunicamycin or BFA treatment has been shown and several studies have confirmed that initial JNK activation is IRE $1 \alpha$ dependent. In the present study, we first identified that the ER stress induced rapid decrease of mitochondrial Ox-Phos, which was not due to a direct effect of ER stress inducers on mitochondria. This rapid impairment in respiration preceded caspase 3 activation and cell death. Cytochrome $c$ release pointed to mitochondrial dependent apoptosis. The rapid impairment in respiration was JNK and ROS dependent as both JNKi and BHA prevented this effect of ER stress inducers. Furthermore, knockdown of Sab as well as the inhibitory Sab KIM1 $_{1}$ peptide blocked the effect of ER stress on mitochondrial respiration. When Sab was knocked down or inhibited, sustained JNK activation did not occur but the very initial JNK activation, presumably due to IRE1 $\alpha$ pathway, was not Sab dependent. Importantly, neither JNKi, BHA, or Sab knockdown inhibited ER stress signaling through IRE1 $\alpha$ (sXBP1) or PERK (CHOP). Furthermore, tunicamycin- or BFA-induced cell death, which was apoptotic as expected, was inhibited by JNKi, BHA, and Sab knockdown indicating that the interplay of JNK with mitochondrial Sab was required for cell death. The early mitochondrial respiratory impairment resulting from the interplay of P-JNK and Sab caused increased ROS production. Superoxide production was demonstrated by addition of P-JNK and ATP directly to isolated mitochondria and was specifically inhibited by Sab KIM1 $_{1}$ peptide. It should be noted that although this JNK effect was previously thought to require damaged mitochondria, ${ }^{29}$ we found that the ROS response occurred in normal liver mitochondria exposed to activated JNK. In this study, we did not examine the specific complexes involved although others have demonstrated that complex I and III are inhibited in other experimental contexts. ${ }^{24}$ The mechanism for how interplay of JNK and Sab leads to impaired respiration is currently under investigation. JNK is known to phosphorylate
Sab on the $C$ terminus ${ }^{26}$ and we found that ATP was required for P-JNK to induce ROS production in isolated mitochondria. How JNK phosphorylation of the cytoplasmic C-terminal side of this protein with one predicted transmembrane domain leads to inhibition of inner membrane electron transport is currently unknown. Nevertheless, it is reasonable to conclude that this leads to the observed impairment of respiration and increase ROS, which then continues to sustain activation of the MAPK cascade, thereby explaining why silencing Sab inhibits sustained JNK activation in ER stress model as well as in APAP and TNF/galactosamine models, triggered by direct toxin effects on mitochondria or TNF receptor signaling, respectively.

We attempted to assess the role of $\mathrm{Ca}^{2+}$ in the tunicamycin-induced impairment of mitochondrial respiration and found through the use of various inhibitors that $\mathrm{Ca}^{2+}$ was dispensable. However, we observed that IP3 mediated calcium release expanded the mitochondrial respiring pool. This is consistent with prior work showing that $\mathrm{Ca}^{2+}$ release from ER and uptake by mitochondria can activate pyruvate, $\alpha$-ketoglutarate, and isocitrate dehydrogenases. ${ }^{30-33}$ Therefore, we considered the possibility that ER stress induced $\mathrm{Ca}^{2+}$ release, and uptake by mitochondria could promote or amplify ROS production when electron transport is blocked by the JNK-Sab mediated effect on mitochondria. Indeed, in isolated mitochondria, addition of calcium amplified the effect of P-JNK on ROS production. The adverse effects of $\mathrm{Ca}^{2+}$ on mitochondria therefore presumably require an increased substrate utilization leading to build-up of reduced complexes due to inhibition by the JNK-Sab effect. Thus, although calcium did not contribute to the JNK-dependent respiratory inhibition, it contributes to the ROS production when electron transport is inhibited.

A final question of importance, not directly addressed in our study, is precisely how sustained JNK activation by the mitochondrial Sab cycle leads to apoptotic cell death. In the APAP model of hepatocyte necrosis, the JNK-Sab interplay leads to amplification of mitochondrial ROS sufficient to induce the MPT. ${ }^{34}$ However, in apoptosis it is likely that the pathway involves MOMP leading to cytochrome $c$ release and caspase activation. JNK is known to phosphorylate proapoptotic $\mathrm{Bcl}_{2}$ family members such as Bax and Bim and antiapoptotic members such as Bcl-extra large $\left(X_{L}\right)$ and myeloid cell leukemia sequence $1(\mathrm{Mcl}-1)$, the former leading to activation and the latter to inhibition. The ultimate outcome is an imbalance of the $\mathrm{BCl}_{2}$ family leading to permeabilization and release of cytochrome $c$ and other intermembrane proteins. ${ }^{35-41}$

In summary, we demonstrated that tunicamycin or BFA, a specific chemical inducer of severe, lethal ER stress in cultured hepatocytes and HeLa cells, caused a rapid impairment of mitochondrial respiration, which is dependent on sustained JNK activation. JNK interacts with Sab, which leads to the inhibition of respiration and ROS production, the latter amplified by calcium release from ER, creating a selfamplification cycle with sustained JNK activation ultimately leading to apoptosis (Figure 4f). Tunicamycin or BFA initiates the process by triggering direct ER-induced $\mathrm{P}$-JNK and $\mathrm{Ca}^{2+}$ release, which target mitochondria to initiate the P-JNK $\rightarrow$ $\mathrm{Sab} \rightarrow \mathrm{ROS}$ cycle. We would like to underscore that our 
a

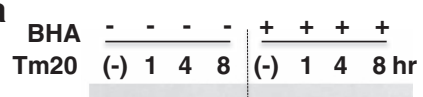

P-JNK $=-ニ=-=ニ=$

JNK

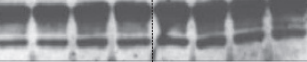

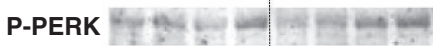

PERK - - - - - -

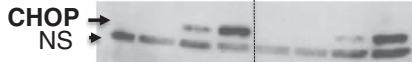

Grp78 $-=--=$

GAPDH
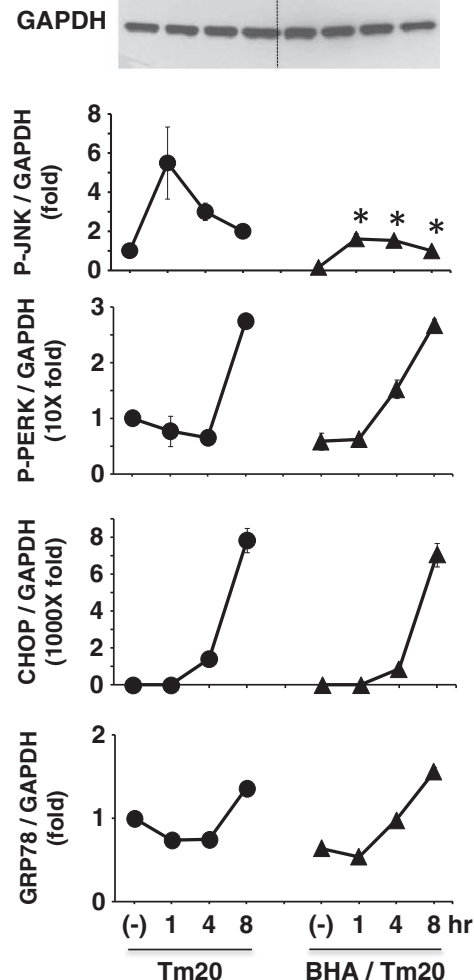

b

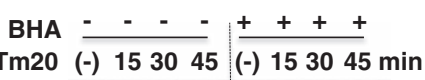

P-JNK =- -

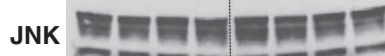
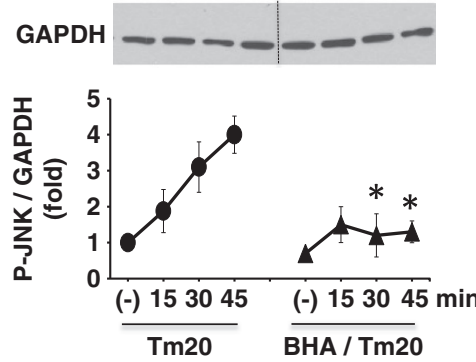
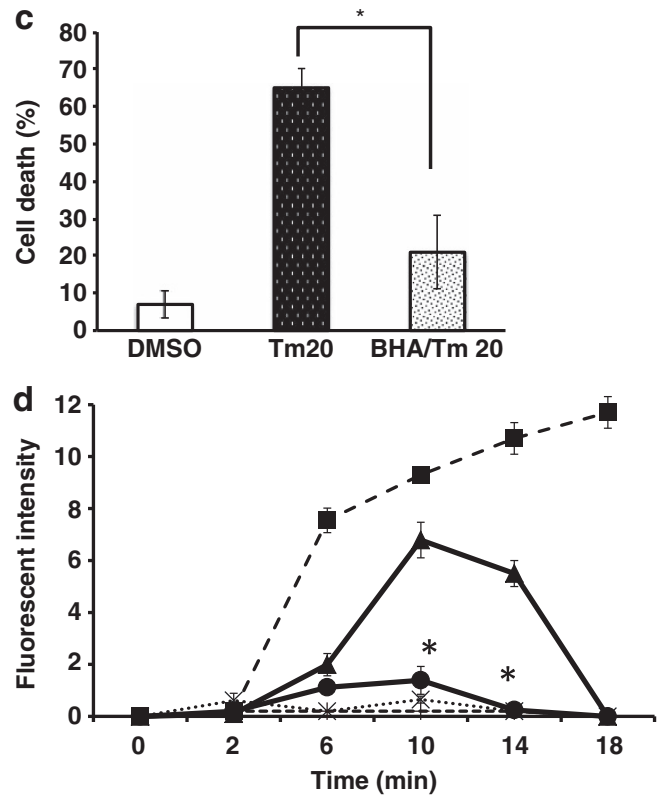

- MitosOX + ATP + Antimycin A

$\Delta$ MitoSOX + ATP + Scramble peptide + JNK(a)

- MitoSOX + ATP + Sab ${ }_{\text {KIM1 } 1}$ peptide + JNK(a)

+ MitosOX + ATP

X Mitosox

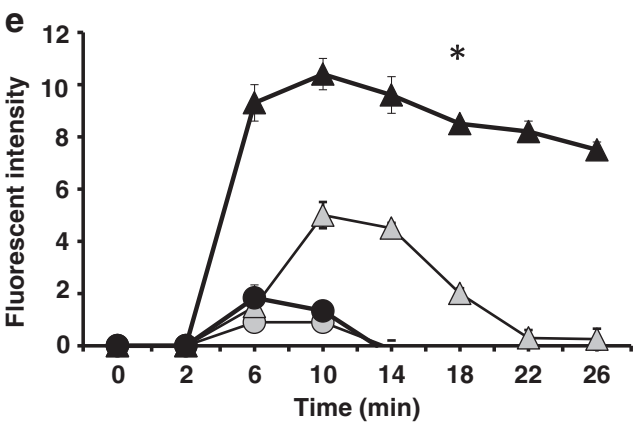

$\Delta\left[\mathrm{Ca}^{2+}\right] 50 \mathrm{nM}+\mathrm{JNK}(\mathrm{a})+\mathrm{ATP}$

- $\left[\mathrm{Ca}^{2+}\right] 50 \mathrm{nM}+\mathrm{JNK}(\mathrm{m})+\mathrm{ATP}$

$\triangle\left[\mathrm{Ca}^{2+}\right] \mathrm{OnM}+\mathrm{JNK}(\mathrm{a})+\mathrm{ATP}$

$\mathrm{O}\left[\mathrm{Ca}^{2+}\right] \mathrm{OnM}+\mathrm{JNK}(\mathrm{m})+\mathrm{ATP}$

f

w ER Stress

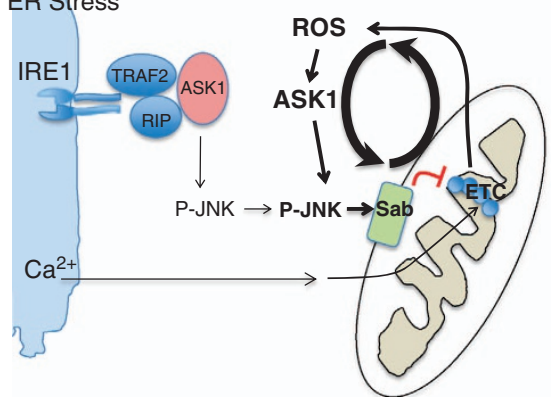


studies represent a model of acute severe chemical induced ER stress, which leads to a large apoptotic effect. Therefore, the extent to which this mechanism contributes to sustained JNK activation, mitochondrial functional impairments and insulin resistance in less severe, nonlethal chronic ER stress, for example, due to overfeeding or excess saturated fatty acid, remains to be studied.

\section{Materials and Methods}

Reagents and animals. P-JNK, PERK, P-PERK, CHOP, Cyt c (Cell Signaling Technology, Danvers, MA, USA), JNK and GRP-78 (Santa Cruz, Dallas, TX, USA), P-CaMKII (Novus, Santa Cruz), Gapdh and $\beta$-actin (Sigma Aldrich, St Louis, MO, USA), IRE1 $\alpha$ (Abcam, Cambridge, MA, USA) and Sab (Proteintech, Abnova, Walnut, CA, USA) were used. DMSO, tunicamycin, BFA, BHA, Z-VADfmk (Sigma Aldrich), JNK inhibitor II (SP600125), Ru360, KN-93 (Calbiochem, EMD-Millipore, Billerica, MA, USA), recombinant JNK1 $\alpha 1 /$ SAPK1c (active and inactive), JNK2 $\alpha 2 / S A P K 1 \alpha$ (active and inactive) (Upstate-Millipore, Billerica, MA USA), BAPTA-AM (Invitrogen, Grand Island, NY, USA) were dissolved as described by the manufacturer. Tat-scrambled peptide (LPSVFGDVGAPSRLPE VSLSP-PRRRQRRKKRG-NH2) and Tat-Sab ${ }_{\text {KIM1 }}$ peptide (GFESLSVPSPLDLSG PRVVAP-PRRRQRRKKRG-NH2) were purchased from Neo Peptide. Sab KIM1 $_{1}$ peptide sequence was the same sequence as JNK binding KIM1 domain of mouse Sab protein. Peptide was dissolved in distilled water and stored in $-80^{\circ} \mathrm{C}$. Male C57BL/6NHsd mice (6-8 weeks of age) were obtained from Harlan Bioproducts for Science Inc. (Indianapolis, IN, USA). Tunicamycin or BFA was dissolved in DMSO (final concentration $0.1 \%$ ).

PMH isolation, culture, treatment and protein extraction. PMHs from wild type or adenoviral shRNA pretreated $\mathrm{C} 57 \mathrm{BL} / 6 \mathrm{~N}$ mice were isolated and cultured as described previously. ${ }^{5}$ Briefly, $5 \mathrm{~h}$ after plating of isolated hepatocytes in seeding medium (DMEM/F12 supplemented with HEPES, L-methionine, L-glutamine, penicillin, streptomycin, $\mathrm{NaHCO}_{3}$, insulin, hydrocortisol, and FBS), the medium was changed to serum free DMEM/F12 culture medium and cells were rested overnight. To the resting medium tunicamycin or DMSO was added and incubated for $0.25,0.5,0.75,1,4,8,16,24 \mathrm{~h}$. At indicated times, hepatocytes were washed twice with DPBS and protein was extracted in RIPA lysis buffer supplemented with protease and phosphatase inhibitors. Whole cell lysate was spun at $20000 \times g$ at $4{ }^{\circ} \mathrm{C}$ for 15 min and supernatant was collected and stored in $-80^{\circ} \mathrm{C}$.

Measurements of respiration by Seahorse XF24 analyzer. PMH were isolated and seeded for $5 \mathrm{~h}$ in collagen coated 24 wells XF24 cell culture microplates. Cells were then rested overnight in serum free, phenol red free $\mathrm{DMEM} / \mathrm{F} 12$ medium. Cells were then removed from the resting medium and washed twice with DMEM running medium (XF assay modified DMEM supplemented with $1 \mathrm{mM}$ sodium pyruvate and $2.5 \mathrm{mM}$ glucose, $\mathrm{pH} 7.4$ ) and incubated at $37^{\circ} \mathrm{C}$ without $\mathrm{CO}_{2}$ for $1 \mathrm{~h}$ to allow cells to pre-equilibrate with the assay medium. Reagents and chemicals for respiratory stress testing were loaded onto XF24 extracellular flux assay plate. Reagent of interest, such as tunicamycin or BFA with or without inhibitors, was diluted in DMEM running medium and loaded into port-A. Oligomycin, CCCP or rotenone (Sigma Aldrich) diluted in DMEM running medium were loaded into port-B, port-C or port-D, respectively. Final concentration in XF24 cell culture microplates were Oligomycin $1 \mu \mathrm{g} / \mathrm{ml}$,
CCCP $20 \mu \mathrm{M}$ or rotenone $20 \mu \mathrm{M}$. Sequence of measurements was as follows unless otherwise described. Basal level of OCR was measured three times, and then port- $A$ was injected and measured seven times for $1-2 h$. The medium was mixed every $10 \mathrm{~min}$ without data acquisition if intervals of OCR measurements were longer than $10 \mathrm{~min}$. At the end of continuous real-time measurement of cellular OCR, port-B, port-C or port-D was injected and OCR was measured two times after each injection to determine mitochondrial or non-mitochondrial contribution of OCR. All measurements were normalized to average of three measurements of basal (starting) level cellular OCR of each well. Each sample was measured in three to five wells. Experiments were repeated three to five times with different cell preparations. Mitochondrial oxidative-phosphorylation was determined by OCR before oligomycin injection minus OCR after oligomycin injection. Mitochondrial proton leak was determined by OCR after oligomycin injection minus OCR after rotenone injection. Non-mitochondrial OCR was determined by OCR after rotenone injection minus OCR of wells without cell. Mitochondrial reserved oxidative capacity was determined by OCR after CCCP injection minus OCR before oligomycin injection. Data were analyzed in groups of wells of each sample cell preparation and statistical analysis was calculated with ANOVA and t-test.

Measurements of ROS. Mitochondria were isolated from wild-type mouse liver as shown before and resuspended in respiration buffer $(70 \mathrm{mM}$ sucrose, $220 \mathrm{mM}$ mannitol, $10 \mathrm{mM} \mathrm{KH}_{2} \mathrm{PO}_{4}, 5 \mathrm{mM} \mathrm{MgCl}$, $2 \mathrm{mM}$ HEPES, $1 \mathrm{mM}$ EGTA $\mathrm{pH} 7.2$ ) and kept in ice. $20 \mu \mathrm{g}$ of isolated mitochondria were diluted to $50 \mu \mathrm{l}$ in respiration buffer with $10 \mathrm{mM}$ pyruvate/2 $\mathrm{mM}$ malate and loaded into each well of fluorescence microtiter plate (Corning, Corning, NY, USA) and kept on ice and covered to avoid exposure to light. For injection port, recombinant active JNK or mutated inactive JNK (Millipore, Billerica, MA, USA) $10 \mathrm{ng}$ per well was diluted to $10 \mu \mathrm{l}$ in respiration buffer and preincubated with $600 \mu \mathrm{M}$ ATP (Sigma Aldrich) and scrambled or Sab KIM $1_{1}$ peptide $10 \mu \mathrm{M}$ at $25^{\circ} \mathrm{C}$ for $30 \mathrm{~min}$. P-JNK + ATP + peptide mix was diluted to $50 \mu \mathrm{l}$ per well in respiration buffer supplemented with $5 \mu \mathrm{M}$ MitoSOX red (Invitrogen) with or without $10 \mu \mathrm{M}$ FeTCPP (Sigma Aldrich). Basal fluorescence level of mitochondria at state II respiration was measured before injection of mixture from injection port, and then measured fluorescence level at 5 min interval using Omega fluorescence microplate reader. For experiments to determine effect of $\mathrm{Ca}^{2+}$ in mitochondrial ROS production, $\left[\mathrm{Ca}^{2+}\right]_{\text {free }}$ was obtained by reciprocal dilution of Zero Free Calcium Buffer and $39 \mu \mathrm{M}$ Free Calcium Buffer (Invitrogen). $50 \mu \mathrm{l}$ of $\left[\mathrm{Ca}^{2+}\right] 0 \mathrm{nM}$ or $50 \mathrm{nM}$ were loaded to microtiter plate on ice, and then $20 \mu \mathrm{g}$ of mitochondria diluted to $50 \mu \mathrm{l}$ in respiration buffer with $10 \mathrm{mM}$ pyruvate $/ 2 \mathrm{mM}$ malate and $5 \mu \mathrm{M}$ MitoSOX was loaded to each well on ice and protect from light. Basal fluorescence intensity was measured for three time, and then $10 \mu \mathrm{l}$ of cocktail of $10 \mathrm{ng}$ activated JNK $\left(\mathrm{JNK}_{(\mathrm{a})}\right)$ or inactive $\mathrm{JNK}\left(\mathrm{JNK}_{(\mathrm{m})}\right)$ and $600 \mu \mathrm{M}$ ATP with or without $10 \mu \mathrm{M}$ FeTCPP was injected to each well. Fluorescence intensity difference of MitoSOX with or without FeTCPP was expressed as fluorescence intensity generated by binding of MitoSOX and superoxide $\left(\mathrm{O}_{2}^{--}\right)$produced from mitochondria.

Cell death assay. PMH were isolated and seeded as described above. At indicated times cell membrane impermeable SYTOX-green ( $1 \mu \mathrm{mol} / \mathrm{L}$; Invitrogen) and cell membrane permeable nuclear stain Hoechst $33258(8 \mu \mathrm{g} / \mathrm{ml}$; Invitrogen) were incubated at $37^{\circ} \mathrm{C}$ for $15 \mathrm{~min}$. Dead cells were identified as SYTOX-green positive due to nuclear staining of impermeable dye. Dead cells were counted from a minimum of 1000 Hoechst 33258 stained cells.

Figure 4 Effect of antioxidant BHA on ER stress induced JNK activation and effect of activated JNK on mitochondrial ROS production. (a) Sustained JNK activation (1-8 h) was inhibited by BHA $100 \mu \mathrm{M}$ preincubation before tunicamycin treatment. Induction of P-PERK, CHOP, and GRP78 expression were not changed by BHA preincubation; ${ }^{*} P<0.05$ versus vehicle control without BHA, $N=3$ experiments. (b) BHA suppressed JNK activation at 30 and 45 min after tunicamycin treatment but not at 15 min (initial activation). (c) BHA prevented tunicamycin-induced cell death; ${ }^{*} P<0.01$ versus $\mathrm{Tm} 20, N=3$ experiments. (d) Sab ${ }_{\mathrm{KIM} 1}$ peptide blocks superoxide $\left(\mathrm{O}_{2}^{*-}\right)$ produced from mitochondria. To wild type isolated mitochondria $(20 \mu \mathrm{g})$ in respiration buffer with pyruvate/malate, premixed $10 \mathrm{ng}$ recombinant active P-JNK (JNK $(\mathrm{a})$ ), ATP and control scrambled peptide or $\mathrm{Sab}_{\mathrm{KI} 1 \mathrm{1}}$ peptide $10 \mu \mathrm{M}$ with MitoSOX (Invitrogen) was added. Superoxide $\left(\mathrm{O}_{2}^{--}\right.$) produced from isolated mitochondria at unstimulated basal (state II) respiration was measured intermittently by Omega fluorescence microplate reader. $\mathrm{Sab}_{\mathrm{KIM} 1}$ peptide blocked superoxide $\left(\mathrm{O}_{2}^{*-}\right)$ production. The data are presented as means \pm S.D. of five wells of each sample for each experiment; ${ }^{*} P<0.01$ (scrambled versus KIM1 peptide), $N=5$ experiments. Antimycin $A$, as a positive control, induced superoxide $\left(\mathrm{O}_{2}^{-}\right)$production, which was not inhibited by KIM1 peptide (not shown). Fluorescence intensity represents the difference between absence and presence of FeTCPP (SOD mimetic). ATP or JNK ${ }_{(a)}$ alone did not significantly increase ROS (not shown). (e) $\left[\mathrm{Ca}^{2+}\right.$ ] enhanced the intensity and duration of production of mitochondrial superoxide $\left(\mathrm{O}_{2}^{--}\right.$) by activated JNK (JNK $(\mathrm{a})$ ). Inactive JNK $\left(\mathrm{JNK}_{(\mathrm{m})}\right)$ with or without ATP did not increase ROS. (See also Supplementary Figures S3 and S4). (f) Model of the role of $\mathrm{JNK}, \mathrm{Sab}, \mathrm{Ca}^{2+}$ and ROS in the interplay of ER stress and mitochondria in sustained JNK activation 
Cleaved-caspase-3 immunocytochemistry and cytochrome $c$ immunofluorescence staining. PMH at indicated times were fixed in 3\% neutral buffered formalin and permeabilized in $80 \%$ methanol. Cells were rinsed in PBS $10 \mathrm{~min}$ for three times and blocked in $5 \%$ BSA-PBS for $1 \mathrm{~h}$ at $25^{\circ} \mathrm{C}$. Cells were then incubated overnight at $4{ }^{\circ} \mathrm{C}$ with cleaved-caspase- 3 antibody (Biocare, Concord, CA, USA) or cytochrome $c$ antibody (Cell Signaling Technology). HRP-conjugated-secondary antibody (Biocare) and DAB (Pierce, Rockford, IL, USA) was used for chromogen development. Nuclei were counterstained with haematoxylin. Cleaved-caspase-3 positive PMH detected as brown colored precipitated DAB were counted from a minimum of 1000 cells. Alexa-488 conjugated-secondary antibody (Invitrogen) was used for laser scanning confocal microscopy (Zeiss 510) (63X magnification) imaging of cytochrome $c$ fluorescence staining in $\mathrm{PMH}$.

Immunoblot analysis. $30-50 \mu \mathrm{g}$ amount of protein of whole cell lysate extracts were loaded and separated on $7.5,10$, or $12 \%$ SDS polyacrylamide gels (Bio-Rad, Hercules, CA, USA) by electrophoresis. Subsequently, proteins were transferred to nitrocellulose membrane and blots were blocked with $5 \%(\mathrm{w} / \mathrm{v})$ nonfat milk dissolved in Tris-buffered saline with Tween 20. The blots were then incubated with the primary and secondary antibodies. Finally, the proteins were detected by Luminol ECL reagent (Thermo Scientific, Waltham, MA, USA). All gels shown are representative from at least three experiments. Densitometric quantification and statistical analysis were determined by four to five experiments.

Reverse transcription PCR to measure XBP1 mRNA splicing. At indicated time, medium was removed and $\mathrm{PMH}$ were quickly covered with RNAprotect cell reagent (Qiagen, Valencia, CA, USA), cell pellet was collected and RNA was isolated using RNA easy kit (Qiagen). $2 \mu \mathrm{g}$ of total RNA was used for reverse transcription PCR using One-step RT-PCR kit (Qiagen). XBP1(S) (spliced form) and XBP1 mRNA was determined by primers ACACGCTTGG GAATGGACAC and CCATGGGAAGATGTTCTGGG. The primers generate amplicons of XBP1(S) 145bp and XBP1 171bp.

Adenoviral shRNA preparation. BLOCK-iT Adenoviral RNAi Expression System (Invitrogen) was used as described before ${ }^{42}$ to generate expression constructs for shRNAs targeting lacZ (shlacZ) and mouse Sab (shSab). The oligo sequences to synthesize the shlacZ construct are $5^{\prime}$-CACCGCTACACAAATC AGCGATTTCGAAAAATCGCTGATTTGTGTAG- $3^{\prime}$ and 5'AAAACTACACAAATCA GCGATTTTTCGAAATCGCTGATTTGTGTAGC-3'. The oligo sequences for the shSab construct are 5'-CACCGGATGACAAGCGGCAGTTTGACGAATCAAACT GCCGCTTGTCATCC-3' and 5'-AAAAGGATGACAAGCGGCAGTTTGATTCGT CAAACTGCCGCTTGTCATCC- 3 '. Mice $(25 \mathrm{~g})$ were tail-vein injected with $1 \times 10^{9}$ infectious units (i.u.) of adenovirus expressing shRNA after purified with Vivapure Adenopack (Sartoriusstedim Biotech, Concord, CA, USA).

Biological replicates and statistical analysis. A minimum of four biological replicates were considered for all cell-based studies. Statistical analyses were performed using the Student's $t$-test or ANOVA for two-way analysis of variance. $P<0.05$ was defined as statistically significant.

\section{Conflict of Interest}

The authors declare no conflict of interest.

Acknowledgements. This work was supported by $\mathrm{NIH}$ grants R01DK067215 (NK) and R01-AA014428 (NK), the USC Research Center for Liver Disease (P30-DK48522) Cellular and Tissue Imaging, Cell Separation and Culture, and Analytical/Metabolic/Instrumentation Cores and the Southern California Research Center for Alcoholic Liver and Pancreatic Disease (P30-AA11999).

\section{Author contributions}

All the authors participated in the design and analysis of the work and writing of the manuscript. SW and TAT performed all the laboratory experiments. NK provided overall guidance.
1. Ozcan U, Cao Q, Yilmaz E, Lee AH, Iwakoshi NN, Ozdelen E et al. Endoplasmic reticulum stress links obesity, insulin action, and type 2 diabetes. Science 2004; 306: 457-461.

2. Gyamfi D, Everitt HE, Tewfik I, Clemens DL, Patel VB. Hepatic mitochondrial dysfunction induced by fatty acids and ethanol. Free Radic Biol Med 2012; 53: 2131-2145.

3. Seki E, Brenner DA, Karin M. A liver full of JNK: signaling in regulation of cell function and disease pathogenesis, and clinical approaches. Gastroenterology 2012; 143: 307-320.

4. Hanawa N, Shinohara M, Saberi B, Gaarde WA, Han D, Kaplowitz N. Role of JNK translocation to mitochondria leading to inhibition of mitochondria bioenergetics in acetaminophen-induced liver injury. J Biol Chem 2008; 283: 13565-13577.

5. Win S, Than TA, Han D, Petrovic LM, Kaplowitz N. C-Jun N-terminal kinase (JNK)-dependent acute liver injury from acetaminophen or tumor necrosis factor (TNF) requires mitochondrial Sab protein expression in mice. J Biol Chem 2011; 286: 35071-35078.

6. Chambers JW, Pachori A, Howard S, Iqbal S, LoGrasso PV. Inhibition of JNK mitochondrial localization and signaling is protective against ischemia/reperfusion injury in rats. J Biol Chem 2013; 288: 4000-4011.

7. Chambers JW, Howard S, LoGrasso PV. Blocking c-Jun N-terminal kinase (JNK) translocation to the mitochondria prevents 6-hydroxydopamine-induced toxicity in vitro and in vivo. J Biol Chem 2013; 288: 1079-1087.

8. Shiraishi H, Okamoto H, Yoshimura A, Yoshida H. ER stress-induced apoptosis and caspase-12 activation occurs downstream of mitochondrial apoptosis involving Apaf-1. J Cell Sci 2006; 119: 3958-3966.

9. Tabas I, Ron D. Integrating the mechanisms of apoptosis induced by endoplasmic reticulum stress. Nat Cell Biol 2011; 13: 184-190.

10. Boya P, Cohen I, Zamzami N, Vieira HL, Kroemer G. Endoplasmic reticulum stressinduced cell death requires mitochondrial membrane permeabilization. Cell Death Differ 2002; 9: 465-467.

11. Urano F, Wang X, Bertolotti A, Zhang Y, Chung P, Harding HP et al. Coupling of stress in the ER to activation of JNK protein kinases by transmembrane protein kinase IRE1. Science 2000; 287: 664-666.

12. Nishitoh H, Matsuzawa A, Tobiume K, Saegusa K, Takeda K, Inoue $K$ et al. ASK1 is essential for endoplasmic reticulum stress-induced neuronal cell death triggered by expanded polyglutamine repeats. Genes Dev 2002; 16: 1345-1355.

13. Marciniak SJ, Yun CY, Oyadomari S, Novoa I, Zhang Y, Jungreis R et al. CHOP induces death by promoting protein synthesis and oxidation in the stressed endoplasmic reticulum. Genes Dev 2004; 18: 3066-3077.

14. Kaplowitz N, Than TA, Shinohara M, Ji C. Endoplasmic reticulum stress and liver injury. Semin Liver Dis 2007; 27: 367-377.

15. Timmins JM, Ozcan L, Seimon TA, Li G, Malagelada C, Backs J et al. Calcium/calmodulindependent protein kinase II links ER stress with Fas and mitochondrial apoptosis pathways. J Clin Invest 2009; 119: 2925-2941.

16. Kato H, Nakajima S, Saito Y, Takahashi S, Katoh R, Kitamura M. mTORC1 serves ER stress-triggered apoptosis via selective activation of the IRE1-JNK pathway. Cell Death Differ 2012; 19: 310-320.

17. Li G, Mongillo M, Chin KT, Harding H, Ron D, Marks AR et al. Role of ERO1-alphamediated stimulation of inositol 1,4,5-triphosphate receptor activity in endoplasmic reticulum stress-induced apoptosis. J Cell Biol 2009; 186: 783-792.

18. Chin KT, Kang G, Qu J, Gardner LB, Coetzee WA, Zito E et al. The sarcoplasmic reticulum luminal thiol oxidase ERO1 regulates cardiomyocyte excitation-coupled calcium release and response to hemodynamic load. FASEB J 2011; 25: 2583-2591.

19. Streb H, Irvine RF, Berridge MJ, Schulz I. Release of $\mathrm{Ca}^{2+}$ from a nonmitochondrial intracellular store in pancreatic acinar cells by inositol-1,4,5-trisphosphate. Nature 1983; 306: 67-69.

20. Buckley BJ, Whorton AR. Tunicamycin increases intracellular calcium levels in bovine aortic endothelial cells. Am J Physiol 1997; 273: 1298-1305.

21. Csordás G, Renken C, Várnai P, Walter L, Weaver D, Buttle KF et al. Structural and functional features and significance of the physical linkage between ER and mitochondria. J Cell Biol 2006; 174: 915-921.

22. Misumi Y, Misumi Y, Miki K, Takatsuki A, Tamura G, Ikehara Y. Novel blockade by brefeldin A of intracellular transport of secretory proteins in cultured rat hepatocytes. J Biol Chem 1986; 261: 11398-11403.

23. Divakaruni AS, Brand MD. The regulation and physiology of mitochondrial proton leak. Physiology 2011; 26: 192-205.

24. Chambers JW, LoGrasso PV. Mitochondrial c-Jun N-terminal kinase (JNK) signaling initiates physiological changes resulting in amplification of reactive oxygen species generation. J Biol Chem 2011; 286: 16052-16062.

25. Chambers JW, Cherry L, Laughlin JD, Figuera-Losada M, Lograsso PV. Selective inhibition of mitochondrial JNK signaling achieved using peptide mimicry of the Sab kinase interacting motif-1 (KIM1). ACS Chem Biol 2011; 6: 808-818.

26. Wiltshire C, Gillespie DA, May GH. Sab (SH3BP5), a novel mitochondria-localized JNK-interacting protein. Biochem Soc Trans 2004; 32: 1075-1077.

27. de Brito OM, Scorrano L. An intimate liaison: spatial organization of the endoplasmic reticulum-mitochondria relationship. EMBO J 2010; 29: 2715-2723.

28. Anelli T, Bergamelli L, Margittai E, Rimessi A, Fagioli C, Malgaroli A et al. Ero1 $\alpha$ regulates $\mathrm{Ca}(2+)$ fluxes at the endoplasmic reticulum-mitochondria interface (MAM). Antioxid Redox Signal 2012; 16: 1077-1087. 
29. Murphy MP. Mitochondrial dysfunction indirectly elevates ROS production by the endoplasmic reticulum. Cell Metab 2013; 18: 145-146.

30. Brookes PS, Yoon Y, Robotham JL, Anders MW, Sheu SS. Calcium, ATP, and ROS: a mitochondrial love-hate triangle. Am J Physiol Cell Physiol 2004; 287: 817-833.

31. Malhotra JD, Kaufman RJ. Endoplasmic reticulum stress and oxidative stress: a vicious cycle or a double-edged sword? Antioxid Redox Signal 2007; 9: 2277-2293.

32. Hanson CJ, Bootman MD, Distelhorst CW, Wojcikiewicz RJ, Roderick HL. Bcl-2 suppresses $\mathrm{Ca}^{2+}$ release through inositol 1,4,5-trisphosphate receptors and inhibits $\mathrm{Ca} 2+$ uptake by mitochondria without affecting ER calcium store content. Cell Calcium 2008; 44: 324-338.

33. Spät A, Szanda G, Csordás G, Hajnóczky G. High- and low-calcium-dependent mechanisms of mitochondrial calcium signalling. Cell Calcium 2008; 44: 51-63.

34. Han D, Dara L, Win S, Than TA, Yuan L, Abbasi SQ et al. Regulation of drug-induced liver injury by signal transduction pathways: critical role of mitochondria. Trends Pharmacol Sci 2013; 34: 243-253.

35. Nutt LK, Pataer A, Pahler J, Fang B, Roth J, McConkey DJ et al. Bax and Bak promote apoptosis by modulating endoplasmic reticular and mitochondrial $\mathrm{Ca}^{2+}$ stores. J Biol Chem 2002; 277: 9219-9225

36. Chae HJ, Kim HR, Xu C, Bailly-Maitre B, Krajewska M, Krajewski S et al. BI-1 regulates an apoptosis pathway linked to endoplasmic reticulum stress. Mol Cell 2004; 15 : 355-366.

37. Oakes SA, Scorrano L, Opferman JT, Bassik MC, Nishino M, Pozzan T et al. Proapoptotic $\mathrm{BAX}$ and $\mathrm{BAK}$ regulate the type 1 inositol trisphosphate receptor and calcium leak from the endoplasmic reticulum. Proc Natl Acad Sci USA 2005; 102: 105-110.
38. Hansson MJ, Månsson R, Morota $\mathrm{S}$, Uchino $\mathrm{H}$, Kallur T, Sumi $\mathrm{T}$ et al. Calcium-induced generation of reactive oxygen species in brain mitochondria is mediated by permeability transition. Free Radic Biol Med 2008; 45: 284-294.

39. Kiviluoto S, Schneider L, Luyten T, Vervliet T, Missiaen L, De Smedt H et al. Bax inhibitor-1 is a novel $\mathbb{I P}_{3}$ receptor-interacting and -sensitizing protein. Cell Death Dis 2012; 3: 367-370.

40. Murakami Y, Aizu-Yokota E, Sonoda Y, Ohta S, Kasahara T. Suppression of endoplasmic reticulum stress-induced caspase activation and cell death by the overexpression of $\mathrm{Bcl}-\mathrm{xL}$ or Bcl-2. J Biochem 2007; 141: 401-410.

41. Moon JL, Kim SY, Shin SW, Park JW. Regulation of brefeldin A-induced ER stress and apoptosis by mitochondrial NADP-dependent isocitrate dehydrogenase. Biochem Biophys Res Commun 2012; 417: 760-764.

42. Than TA, Lou H, Ji C, Win S, Kaplowitz N. Role of cAMP-responsive element-binding protein (CREB)-regulated transcription coactivator 3 (CRTC3) in the initiation of mitochondrial biogenesis and stress response in liver cells. J Biol Chem 2011; 286: 22047-22054

(c) (i) () $\Theta$ Cell Death and Disease is an open-access journal published by Nature Publishing Group. This work is licensed under a Creative Commons Attribution-NonCommercialNoDerivs 3.0 Unported License. To view a copy of this license, visit http://creativecommons.org/licenses/by-nc-nd/3.0/

Supplementary Information accompanies this paper on Cell Death and Disease website (http://www.nature.com/cddis) 